Wiraraja Medika : Jurnal Kesehatan
https://www.ejournalwiraraja.com/index.php/FIK
2088-415x (Print) |2685-9998 (online)

\title{
Pengaruh Terapi Dzikir Terhadap Kadar Glukosa Darah Pasien Diabetes Melitus Tipe 2
}

\author{
Sitti Fatimah ${ }^{1}$, Erna Rochmawati ${ }^{2}$, Arianti ${ }^{3}$ \\ ${ }^{1,2,3}$ Program Studi Magister Keperawatan, Universitas Muhammadiyah Yogyakarta \\ 1fatimah.st.pasca@gmail.com* ${ }^{*}$,erna.rochmawati@umy.ac.id, ariimoon@gmail.com \\ *Corresponding author
}

\begin{tabular}{l}
\hline INFORMASI ARTIKEL \\
\hline Received: $21-04-2020$ \\
Revised: 06-05-2020 \\
Accepted: $25-05-2020$
\end{tabular}
ABSTRAK
Diabetes melitus merupakan suatu penyakit dengan gangguan metabolisme
kronis berupa meningkatnya kadar glukosa darah yang disebabkan oleh
terganggunya sekresi insulin atau efikasi insulin. Penatalaksanaan penyakit
diabetes dapat dilakukan secara farmakologi maupun nonfamakologi. Salah
satu terapi nonfarmakologis adalah dengan terapi dzikir. Desain penelitian
menggunakan quasy esperiment with control group pre-post test design.
Sampel berjumlah 40 responden dengan teknik simple random sampling.
Sampel penelitian dibagi menjadi 2 kelompok yaitu kelompok kontrol dan
kelompok intervensi yang masing-masing berjumlah 20 responden. Analisa
data menggunakan independent t-test. Hasil penelitian menunjukkan bahwa
terapi dzikir terapi dzikir berupa kalimat thayibah, asmaul husna dan doa
yang dilakukan setiap hari selama 2 minggu secara signifikan dapat
menurunkan kadar glukosa darah pasien $(\mathrm{p}=0.000)$ atau p $<0.05$.

\begin{tabular}{l}
\hline Kata kunci: \\
Terapi Dzikir \\
Kadar Glukosa Darah \\
Diabetes Melitus Tipe 2
\end{tabular}

Key word:

Dhikr Therapy

Blood Glucose Level

Type 2 Diabetes

Mellitus

\section{ABSTRACT}

Diabetes mellitus is a chronic disease with metabolic disorders in the form of increased blood glucose levels caused by disruption of insulin secretion or insulin efficacy. Management of diabetes can be done by pharmacology or nonphamacology therapy. One of the nonpharmacological therapies is dhikr therapy. The study design used quasy experiment with the control group prepost test design. The collected samples are 40 diabetes patients with simple random technique. The research sample was divided into 2 groups,control and intervention group, each of which was 20 respondents. Data analysis uses independent t-test. The results showed that dzikir therapy of sentences thayibah, asmaul husna and prayers performed every day for 2 weeks could significantly reduce patients blood glucose levels $(\mathrm{p}=0.000)$ or $\mathrm{p}<0.05$.

\section{PENDAHULUAN}

Diabetes melitus merupakan penyakit kronis progresif yang ditandai oleh adanya peningkatan kadar glukosa darah yang tinggi atau hyperglicemia (Kerner \& Bruckel, 2014). Diabetes Melitus (DM) merupakan penyakit dengan jumlah pasien dewasa terbanyak di dunia. Berdasarkan data World Health Organization (WHO) tahun 2016 menyatakan prevalensi global diabetes orang dewasa di atas 18 tahun telah meningkat dari 4,7\% dengan jumlah 108.000.000 jiwa pada tahun 1980 menjadi $8,5 \%$ atau 422.000 .000 jiwa pada tahun 2014. International Diabetes Federation (IDF) tahun 2017 menunjukkan bahwa terdapat sekitar 1.600.000 kasus kematian secara langsung disebabkan oleh diabetes melitus. IDF juga melaporkan bahwa
Indonesia menempati urutan ke-7 dengan jumlah 10.000.000 pasien dan diperkirakan pada tahun 2040 Indonesia menempati urutan ke-6 dengan jumlah 16.200.000 pasien diabetes.

Prevalensi diabetes di Indonesia terus mengalami peningkatatan. Data Riset Kesehatan Dasar (RISKESDAS) tahun 2018 menunjukkan bahwa terjadi peningkatan jumlah pasien DM dari 6,9\% pada tahun 2013 menjadi 10,9\% pada tahun 2018. Peningkatan jumlah pasien tersebut banyak terjadi terutama di kota-kota besar salah satunya adalah Daerah Istimewa Yogyakarta (DIY) yang merupakan wilayah pasien diabetes terbanyak ketiga setelah DKI Jakarata dan Kalimantan Timur. Penatalaksanaan penyakit diabetes melitus meliputi terapi farmakologi maupun 
nonfarmakologi. Terapi farmakologi yaitu terapi dengan menggunakan menggunakan obat-obatan sedangkan nonfarmakologi tanpa penggunaan obat-obatan (ADA, 2018). Terapi nonfarmakologi yang dapat diberikan pada pasien berupa terapi alternatif komplementer yaitu mind body Therapy yang bertujuan untuk memberikan efek relaksasi dan meningkatkan kemampuan berfikir. (Lindquist, 2014). Salah satu terapi mind body yang dapat memberikan efek relaksasi adalah terapi dzikir karena didalamnya terdapat unsur kepercayaan (Priya \& Karla, 2017).

Terapi dzikir diharapkan akan lebih mudah dilakukan karena sesuai dengan akidah seorang muslim dan hal ini didukung oleh mayoritas penduduk Indonesia yang beragama Islam dengan jumlah 207.176.162 jiwa dari total populasi 237.641.326 jiwa (Badan Pusat Statistik, 2013).Terapi religious seperti dzikir dapat dilakukan sebagai bentuk upaya dalam penyembuhan penyakit (Sagiran, 2017). Menurut Newlin (2008) bahwa terapi spiritual merupakan faktor penting dalam perawatan pasien diabetes. Terapi dzikir dapat memberikan efek relaksasi dan ketenangan jiwa yang dapat merangsang HPA Axis untuk menurunkan produksi hormon kortisol sehingga dapat menurunkan kadar glukosa darah (Amir et al., 2018).

\section{METODE}

Penelitian ini menggunakan quasi experiment pre-post test with control group. Populasi pada penelitian ini adalah pasien diabetes melitus yang berada di wilayah kerja Puskesmas Gamping 2. Teknik pengambilan sampel menggunakan simple random sampling dengan kriteria inklusi yaitu pasien terdiagnosis diabetes melitus tipe 2, beragama islam, berusia $<65$ tahun, pasien mampu membaca dan menulis dan tidak mengalami gangguan/masalah pendengaran dan bersedia menjadi responden penelitian. Jumlah sampel penelitian adalah 40 responden yang terbagi menjadi 2 yaitu, 20 responden kelompok intervensi dan 20 responden kelompok kontrol.

Tahap awal dilakukan pre test pengukuran glukosa darah yang dilakukan pemeriksaan langsung oleh petugas laboratorium dengan menggunakan glucometer terumo medisafe-ex milik Puskesmas Gamping 2 yang telah memiliki ijin dari kementrian Kesehatan RI dan setiap 3 bulan sekali dilakukan quality control oleh Dinas Kesehatan Kabupaten Sleman bagian pengelolaan obat dan alat kesehatan. Kelompok intervensi mendapatkan terapi oral diabetes serta diberikan terapi dzikir dengan cara membaca(melafalkan) kalimat thayibah, asmaul husna dan do'a sekaligus mendengarkan lantunan dzikir yang sama yang dibantu dengan menggunakan buku panduan dzikir serta MP3 Player.

Terapi dzikir dilakukan dengan durasi 15 menit setiap hari selama 2 minggu pada sore hari setelah sholat ashar sampai sebelum sholat magrib atau sebelum matahari terbenam. Peneliti melakukan follow up pelaksanaan terapi dzikir dengan mengingatkan pasien via sms/telepon serta mengisi lembar terapi harian dan peneliti juga melakukan kunjungan rumah 2 kali setiap minggunya. Kelompok kontrol mendapatkan terapi oral diabetes dari puskesmas tanpa diberikan terapi dzikir. Setelah 2 minggu, dilakukan post test pengukuran glukosa darah. analisis dengan menggunakan software SPSS yang terbagi menjadi 2 yaitu analisis univariat untuk mengetahui distribusi karakteristik responden, dan kadar glukosa darah serta analisis bivariat menggunakan independent t-test untuk mengetahui pengaruh dzikir terhadap kadar glukosa darah pasien.

\section{HASIL PENELITIAN}

Tabel 1. Distribusi Karakteristik Berdasarkan Demografi Responden

\begin{tabular}{|c|c|c|c|c|}
\hline \multirow{3}{*}{$\frac{\text { Karakteristik }}{\text { Usia }}$} & \multicolumn{4}{|c|}{ Kelompok } \\
\hline & \multicolumn{2}{|c|}{ Intervensi } & \multicolumn{2}{|c|}{ Kontrol } \\
\hline & $f$ & $\%$ & $f$ & $\%$ \\
\hline 25-35 tahun & 1 & $5 \%$ & 0 & $0 \%$ \\
\hline 36-45 tahun & 4 & $20 \%$ & 2 & $10 \%$ \\
\hline 46-55 tahun & 12 & $60 \%$ & 10 & $50 \%$ \\
\hline 56-65 tahun & 3 & $15 \%$ & 8 & $40 \%$ \\
\hline \multicolumn{5}{|l|}{ Jenis kelamin } \\
\hline Laki-laki & 4 & $20 \%$ & 4 & $20 \%$ \\
\hline Perempuan & 16 & $80 \%$ & 16 & $80 \%$ \\
\hline \multicolumn{5}{|l|}{ Pendidikan } \\
\hline SD & 5 & $25 \%$ & 8 & $40 \%$ \\
\hline SMP & 8 & $40 \%$ & 9 & $45 \%$ \\
\hline SMA & 5 & $25 \%$ & 2 & $10 \%$ \\
\hline PT & 2 & $10 \%$ & 1 & $5 \%$ \\
\hline \multicolumn{5}{|l|}{ Pekerjaan } \\
\hline IRT & 10 & $50 \%$ & 13 & $65 \%$ \\
\hline Buruh & 4 & $20 \%$ & 2 & $10 \%$ \\
\hline Wiraswasta & 4 & $20 \%$ & 4 & $20 \%$ \\
\hline PNS & 2 & $10 \%$ & 1 & $5 \%$ \\
\hline \multicolumn{5}{|l|}{ Pendapatan } \\
\hline$<1.500 .000$ & 12 & $60 \%$ & 11 & $55 \%$ \\
\hline$>1.500 .000$ & 8 & $40 \%$ & 9 & $45 \%$ \\
\hline
\end{tabular}


Tabel 1 menunjukkan sebagian besar responden berada pada rentang usia 46-55 tahun, berjenis kelamin perempuan, pendidikan SMP, pekerjaan IRT, serta berpendapatan $<1.500 .000$.

Tabel 2. Distribusi Karakteristik Berdasarkan Penyakit dan Dukungan Keluarga

\begin{tabular}{ccccc}
\hline \multirow{2}{*}{ Karakteristik } & \multicolumn{5}{c}{ Kelompok } \\
\cline { 2 - 5 } & \multicolumn{3}{c}{ Intervensi } & \multicolumn{2}{c}{ Kontrol } \\
\cline { 2 - 5 } & $f$ & $\%$ & $f$ & $\%$ \\
\hline Lama Sakit : & 3 & $15 \%$ & 2 & $10 \%$ \\
< 1 Tahun & 16 & $80 \%$ & 18 & $90 \%$ \\
1-5 Tahun & 1 & $5 \%$ & 0 & $0 \%$ \\
>5 TAhun & & & & \\
\hline Komplikasi : & 7 & $35 \%$ & 5 & $25 \%$ \\
\hline Ada & 13 & $65 \%$ & 15 & $75 \%$ \\
\hline Tidak Ada & & & & \\
\hline Minum Obat & 6 & $30 \%$ & 5 & $25 \%$ \\
\hline Rutin & 14 & $70 \%$ & 15 & $75 \%$ \\
Tidak Rutin & & & &
\end{tabular}

\begin{tabular}{ccccc}
\hline Pola Makan : & & & & \\
\hline Teratur & 5 & $25 \%$ & 6 & $30 \%$ \\
Tidak Teratur & 15 & $75 \%$ & 14 & $70 \%$ \\
\hline Olah Raga : & & & & \\
\hline Rutin & 2 & $10 \%$ & 3 & $15 \%$ \\
Tidak Rutin & 18 & $90 \%$ & 17 & $85 \%$ \\
\hline Dukungan & & & & \\
Keluarga : & & & & \\
\hline Kadang - & 12 & $60 \%$ & 14 & $70 \%$ \\
Kadang & 5 & $25 \%$ & 5 & $25 \%$ \\
Sering & 3 & $15 \%$ & 1 & $5 \%$ \\
Selalu & & & & \\
\hline
\end{tabular}

Tabel 2 menunjukkan sebagian besar responden lama mendeirta diabetes 1-5 tahun, manajemen diabetes berupa frekuensi minum obat yang tidak ritun, pola makan yang tidak teratur, dan olah raga tidak teratur serta dukungan keluarga yang masih kurang.

Tabel 3. Kadar Glukosa Darah Sebelum dan Sesudah Pemberian Terapi Dzikir

\begin{tabular}{ccccc}
\hline \multirow{2}{*}{ Kelompok } & \multicolumn{2}{c}{ Glukosa Darah (Pre) } & \multicolumn{2}{c}{ Glukosa Darah (Post) } \\
\cline { 2 - 5 } & mean $\pm S D$ & min-max & mean $\pm S D$ & min-max \\
\hline Intervensi & $247.25 \pm 100.83$ & $130-456$ & $179.90 \pm 76.59$ & $85-358$ \\
\hline Kontrol & $253.25 \pm 100.61$ & $128-451$ & $279.60 \pm 92.42$ & $141-455$ \\
\hline
\end{tabular}

Tabel 3 menunjukkan nilai rata-rata kadar glukosa darah pada kelompok intervensi mengalami penurunan yaitu dari 247.25 menjadi 179.90 sedangkan kelompok kontrol mengalami kenaikan yaitu dari 253.25 menjadi 279.60 .

\section{Analisis Bivariat}

Tabel 4. Hasil Uji Independet t-test

\begin{tabular}{lcc}
\hline \multicolumn{1}{c}{ Kelompok } & Variabel & p value \\
\hline $\begin{array}{l}\text { Kelompok } \\
\text { Intervensi dan }\end{array}$ & Glukosa & 0.000 \\
Kontrol $(\mathrm{n}=40)$ & Darah & \\
\hline
\end{tabular}

Tabel 4 merupakan hasil analisis uji statistik dengan menggunakan uji Independet t-test antara kelompok intervensi dan kontrol terhadap kadar glukosa darah, hasilnya menunjukkan bahwa terapi dzikir secara signifikan berpengaruh terhadap penurunan kadar glukosa darah ( $p$ value $<0.05$ ).

\section{PEMBAHASAN}

A. Analisis Univariat

1. Karakteristik responden berdasarkan data demografi

\section{a. Usia}

Tabel 1 menunjukkan sebagian besar responden berada rentang usia 46-55 tahun. Hasil penelitian ini sejalan dengan penelitian oleh Ramadhan \& Hanum (2016) di Puskesmas Jayabaru Banda Aceh menunjukkan bahwa pasien diabetes tipe 2 terbanyak berada pada usia diatas 46 Tahun yaitu sebesar 83,5\%. Kejadian penyakit diabetes tipe 2 meningkat seiring dengan bertambahnya usia (Kerner \& Bruckel, 2014). Hal ini dikuatkan dengan pendapat Fatimah (2015) yang menjelaskan bahwa usia $>45$ tahun beresiko penyakit diabetes.

Peningkatan resiko terjdainya DM dapat disebabkan oleh kemunduran fungsi fisiologis dan proses metabolisme yang terjadi pada lanjut usia yang mengakibatkan terjadinya disfungsi seluler pada sel beta pancreas dan menyebabkan resistensi insulin yang berdampak pada penyerapan glukosa sehingga dapat terjadi peningkatan glukosa darah (Bonomini et al., 2015). Semakin meningkatnya usia juga berpengaruh pada penurunan kemampuan perawatan diri khuhusnya tatalaksana diabetes melitus (Kusnanto, 2015). 
b. Jenis Kelamin

Karakteristik berdasarkan jenis kelamin responden sebagian besar adalah berjenis kelamin perempuan (Tabel 1). Hasil penelitian ini sejalan dengan penelitian dari Livana, et al., (2018) di Kabupaten Kendal sebagian besar yang didiagnosis diabetes melitus adalah berjenis kelamin perempuan yaitu sebesar 54\%. Menurut data Riskesdas (2018) melaporkan bahwa perempuan memiliki prevalensi diabetes tertinggi dibandingkan laki-laki. Perempuan lebih berisiko menderita penyakit diabetes disebabkan oleh beberapa hal diantaranya adalah proses menopause dan peran hormonal (Rayanagoudar et al.,2016) dan kurangnya aktivitas fisik (Trento et al.,2014).

c. Pendidikan

Tingkat pendidikan responden terbanyak adalah SMP (Tabel 1). Hasil penelitian ini sejalan dengan penelitian Hendriati., et al (2018) bahwa sebagian besar pasien diabetes di Medan juga berpendidikan SMP. Tingkat pendidikan yang rendah mempunyai angka kejadian diabetes melitus yang lebih tinggi dibandingkan dengan yang berpendidikan tinggi (Tao et al., 2016). Tingkat pendidikan yang rendah cenderung diikuti pengetahuan yang rendah serta status sosial ekonomi yang rendah yang akan berpengaruh terhadap pemeliharaan kesehatan yang kurang dan berdampak pada peningkatan risiko diabetes (Allorerung et al., 2016).

d. Pekerjaan

Status pekerjaan responden terbanyak adalah IRT (tabel 1). Penelitian oleh Zainudin et al., (2015) juga menunjukaan bahwa sebagian besar pasien diabetes adalah IRT dengan presentasi sebesar 46,7 \%. Menurut Al-Tuwijri et al., (2007) Ibu rumah tangga sebagian besar menghabiskan waktu dirumah dan hal ini memungkinkan kurangnya aktivitas fisik sehingga juga dapat meningkatkan risiko terjadinya diabetes.

e. Pendapatan

Hasil pendapatan perbulan responden sebagian besar adalah $<1.500 .000$ (tabel 1). Hal ini dapat dihubungkan dengan banyaknya reponden yang berprofesi sebgai IRT. Hasil penelitian ini sejalan dengan penelitian sebelumnya oleh Chye et al., (2015) yang menunjukkan pasien diabetes di Malaysia juga berpendapatan rendah.
Menurut Walker et al., (2014) bahwa status ekonomi yang rendah mempunyai risiko diabetes yang lebih tinggi.

2. Karakteristik responden bedasarkan penyakit dan dukungan keluarga

a. Lama sakit

Tabel 2 menunjukkan lama pasien menderita penyakit DM sebagian besar adalah 1-5 tahun. Hal ini sejalan dengan penelitian sebelumnya oleh Ramdhani (2016) di RS Kardinah Kota Tegal yang menunjukkan pasien diabetes melitus terbanyak adalah dibawah dari 5 tahun.

Menurut Nanayakkara et al.,(2017) terdapat hubungan lama diabetes dengan komplikasi yaitu, semakin lama pasien menderita diabetes akan semakin berisiko mengalami komplikasi.

b. Komplikasi

Tabel 2 menunjukkan sebagian besar pasien tidak memiliki komplikasi Hasil penelitian ini sejalan dengan Kartika et al.,(2016) yang juga menunjukkan bahwa pasien diabetes yang berada pada lima tahun pertama sebagian besar tidak memiliki komplikasi. Menurut Zimmet (2009) hal ini dipengaruhi oleh selama menderita diabetes jika diimbangi dengan penatalaksanaan manajemen diabetes yang baik dapat maka akan dapat menurunkan risiko terjadinya komplikasi.

c. Manajemen Diabetes

Manajemen diabetes meliputi beberapa hal yaitu pengaturan pola makan, aktivitas fisik serta penggunaan obat diabetes (ADA, 2018).

1) Frekuensi minum obat

Berdasarkan hasil penelitian yang terlihat pada Tabel 2 bahwa frekuensi minum obat responden sebagain besar adalah tidak rutin. Hal ini sejalan dengan penelitian Harista \& Lisiswanti (2015) menunjukkan sebagian besar pasien yang terdiagnosis diabetes di Lampung tidak rutin mengkonsumsi obat. Hasil yang sama juga ditemukan pada penelitian dari Alfian et al., (2015) di polikinik RSUD Dr. Moch Ansari Banjarmasin menunjukkan sebagaian pasien diabetes mempunyai kepatuhan minum obat yang rendah.

Data RISKESDAS (2018) melaporkan bahwa sebagian besar pasien diabetes tidak rutin mengkonsumsi obat dengan beberapa alasan diantaranya yaitu lupa untuk mengkonsumsi obat ataupun karena merasa sudah sehat. 
2) Pola makan

Pengaturan pola makan pasien diabetes dalam penelitian ini sebagian besar adalah tidak rutin (Tabel 2). Hal ini sejalan dengan penelitian Siregar \& Hidayat (2017) di Puskesmas Kecamatan Gambir Jakarta menjelaskan bahwa sebagian besar pasien terdiagnosis diabetes tidak mengatur pola makan. Penelitian dari Dewi et al., (2018) di Wilayah Puskesmas Sudiang Raya Makassar menunjukkan sebagaian besar pasien diabetes tidak melakukkan pengaturan pola makan yaitu sebesar 91,7\%. Menurut Atkins \& Bowler (2016) menjelaskan bahwa pola makan berhubungan dengan kebiasaan atau perilaku seseorang dalam mengkonsumsi makanan dan perilaku tersebut tidak mudah untuk dirubah.

\section{3) Olah Raga}

Frekuesi olahraga yang dilakukan oleh responden sebagian besar adalah tidak rutin (Tabel 2). Hasil ini sejalan dengan penelitian sebelumnya oleh Sari et al., (2017) di Puskesmas Kabupaten Pati yang menunjukkan sebagian besar pasien terdiagnosis diabetes tidak rutin melakukan olahraga. Penelitian lainnya dari Nur et al.,(2016) di RSU dr. Fauziah Bireuen Aceh menunjukkan bahwa sebagian pasien terdiagnosis diabetes juga tidak rutin berolahraga. Menurut Sylow et al.,(2016) kurangnya aktivitas fisik atau olah raga dapat menstimulasi transduksi sinyal yang dapat mepengaruhi sensitivitas insulin sehingga dapat meningkatkan risiko diabetes melitus.

4) Dukungan Keluarga

Dukungan keluarga pasien sebagaian besar adalah kurang atau kadang-kadang (Tabel 2). Hasil ini sejalan dengan penelitian oleh Bertalina \& Purnama (2016) di RSUD Abdul Moeloek menunjukkan sebagian besar pasien diabetes kurang mendapat dukungan keluarga. Menurut Arifin \& Damayanti (2015) dukungan keluarga dapat berdampak pada kepatuhan manajemen diabetes. Hal tersebut diperkuat oleh hasil penelitian Song et al.,(2017) yang menunjukkan bahwa dukungan keluarga mampu meningkatkan kemampuan serta kepatuhan pasien dalam manajemen diabetes.

3. Nilai kadar glukosa darah

Tabel 3 menunjukkan bahwa nilai ratarata kadar glukosa darah pada kelompok intervensi mengalami penurunan. Hasil penelitian ini sejalan dengan Susanti (2014) bahwa terapi latihan pasrah diri dengan menggunakan terapi relaksasi dzikir menunjukkan adanya penurunan kadar glukosa darah dari nilai rata-rata 249.8 menjadi 198.95. Hasil penelitian lainnya dari Habbiburahman (2018) yang juga menunjukan bahwa setalah diberikan intervensi dzikir terdapat penurunan ratarata glukosa darah dari 175,65 menjadi 167,06 .

Dari beberapa penelitian diatas menunjukkan bahwa adanya perbedaan dalam penurunan kadar glukosa darah pasien. Hasil penelitian ini (Tabel 3) menunjukkan bahwa adanya penurunan kadar glukosa darah yang lebih dibandingkan penelitian sebelumnya. Peneliti berasumsi bahwa hal ini dilatarbelakangi oleh perbedaan dalam cara berdzikir. Pada penelitian ini terapi dzikir dilakukan dengan cara membaca serta mendengarkan lantunan dzikir sedangkan pada penelitian sebelumnya hanya membaca dzikir tanpa mendengarkan.

B. Analisis Bivariat

Tabel 4 menunjukkan hasil uji independent $t$-test pada kelompok intervensi dan kelompok kontrol terhadap kadar glukosa darah dengan nilai ( $p$ value $=0.000$ ) atau $p<0.05$ sehingga dapat diinterpretasikan bahwa terapi dzikir yang diberikan secara signifikan berpengaruh terhadap penurunan kadar glukosa darah.

Terapi spiritualitas seperti dzikir sangat penting bagi pasien muslim karena dapat memberikan respon psikologis yang baik pada pasien diabetes dikarenakan adanya ketenangan yang diperoleh saat merasa dekat dengan Tuhan (Jafari et al.,2014). Sebagaimana dalam firman Allah "(yaitu) orang-orang yang beriman dan hati mereka manjadi tentram dengan mengingat Allah. Ingatlah, hanya dengan mengingati Allah-lah hati menjadi tentram" (Q.S. Ar Ra'd : 28).

Terapi dzikir dalam penelitian ini dilakukan dengan cara membaca serta mendengarkan kalimat thayibah, asmaul husna dan doa selama 2 minggu yang dibantu dengan menggunakan buku panduan dzikir serta MP3 yang berisi lantunan dzikir yang sama. Hal ini bertujuan untuk memudahkan responden untuk mengerti dan memahami arti dzikir. Menurut Khoirunnisa (2016) memahami dan mengamalkan dzikir secara berkelanjutan dapat memberikan dampak yang positif terhadap aspek emosional, memperoleh 
ketenangan hati dan rasa sabar dan dapat menjadikan individu mampu mengendalikan serta mampu memotivasi dirinya sendiri.

Ketika berdzikir, telinga menerima respon suara dengan menggetarkan membran timpani. Getaran tersebut selanjutnya dirubah sebagai impuls elektrik melalui nervus auditorius yang dihantarkan ke sistem limbik yang dilajutkan kembali ke hipokampus dan sampai pada amigdala. Fungsi amigdala adalah mempengaruhi ransangan emosional dengan memberikan ketenangan (Priya \& Klara, 2017).

Terapi dzikir juga dapat menstimulasi sistem saraf pusat untuk mengeluarkan hormon endorphin enkefalin yang membuat perasaan senang sehingga membuat pasien lebih tenang (Kuswandari, 2016). Ketenangan yang dirasakan pasien akan mempengaruhi jalur fisiologis yaitu Hypoyhalamus Pytutary Axis (HPA). Saraf Simpatik melalui medula adrenal akan menekan produksi epinefrin untuk menurunkan produksi glucagon. Selain itu Hipotatalamus juga akan menstimulasi kelenjar pituitari untuk melepaskan Adrenocorticotropic Hormone (ACTH) yang menstimulasi cortex adrenal yang juga turut menurunkan produksi hormon kortisol yang akhirnya dapat menurunkan produksi glukosa darah (Hackett \& Steptoe, 2017).

\section{KESIMPULAN}

Terdapat pengaruh terapi dzikir terhadap penurunan kadar glukosa darah pasien diabetes melitus tipe 2 .

\section{DAFTAR PUSTAKA}

Alfian, R. (2015). Korelasi Antara Kepatuhan Minum Obat dengan Kadar Gula Darah pada Pasien Diabetes Melitus Rawat Jalan di RSUD Dr. H. Moch. Ansari Saleh Banjarmasin. Jurnal Pharmascience, 2(2), 15-23.

Allorerung, D, L., Sekeon, S,A, S., \& Joseph, W, B, S. (2016). Hubungan Antara Umur, Jenis Kelamin Dan Tingkat Pendidikan Dengan Kejadian Diabetes Melitus Tipe 2 Di Puskesmas Ranotana Weru Kota Manado. Jurnal Seluruh, 8(3).24-25.

Amir, F., Mastutik, G., Hasinuddin., \& M., Putra, T, S. (2018). Dhikr and Relaxation Improve Stress Preception and Reduce Blood Cortisol Level In
Type 2 Diabetes Mellitus Patients With OAD. Journal Folia Medica Indonesia Unair. 54(4) 249-255. http:// doi.org/10.20473/fmi.v54i4.10707

Arifin, Damayanti, S. (2015). Hubungan Dukungan Keluarga Dengan Kepatuhan Diet Diabetes Melitus Tipe 2 di Poli Penyakit Dalam RSUP dr. Soeradji Tirtonegoroklaten. Jurnal Keperawatan Respati Yogyakarta. 2(2), 37-44. https://doi.org/10.35842/jkry.v2i2.1 70.

Atkins, P \& Bowler, I. (2016). Food in Society. Routledge Taylor \& Francis Group. USA

American Diabetes Asociation. (2018). Standars of Medical Care in Diabetes $2018 . \quad 14-37 . \quad \mathrm{http}: / /$ doi.org/10.2337/dc18-Sint01.

Bertalina \& Purnama. (2016). Hubungan Lama Sakit, Pengetahuan, Motivasi Pasien dan Dukungan Keluarga dengan Kepatuhan Diet Pasien Diabetes Mellitus. Jurnal Kesehatan, 7(2), 329-340. https://doi.org/10.26630/jk.v7i2

Dewi, T., Amir, A., \& Sabir, M. (2018). Kepatuhan Diet Pasien Dm Berdasarkan Tingkat Pengetahuan Dan Dukungan Keluarga Di Wilayah Puskesmas Sudiang Raya. Jurnal Media Gizi Pangan. 25(1), 55-63. https://doi.org/10.32382/mgp.v25il. 60

Fatimah, R,N. (2015). Diabetes Melitus Tipe 2. Medical Journal of Lampung University. 4(5), 94-112

Habiburrahman., Hesneli, Y., \& Amir, Y. (2018). Efektivitas Terapi Dzikir Terhadap Kadar Glukosa Darah Pada Pasien Diabetes Melitus Tipe II. Jurnal Ners Indonesia, 8(2), 132-144. http://dx.doi.org/10.30652/jni.v8i2

Hackett, R, A., \& Steptoe, A (2017). Type 2 Diabetes Mellitus and Psychological Stress- a midifiable risk factor. Nature Reviews Endocrinology, 13(9), 547560.

http://doi.org/10.1038/nrendo.2017. 64

International Diabetes Federation. (2015). IDF Diabetes Atlas $7^{\text {th }}$ Edition. diakses 12 Juli 2018 dari http://www. diabetes atlas.org 
Jafari, N., Farajzadegan, Z., Loghmani, A., \& Majlesi, M. (2014). Spiritual Well-Being and Quality of Life of Iranian Adults with Type 2 Diabetes. Journal of Evidance-Based Complementary and Alternative Medicine. 14(2), 1-8 https://doi.org/10.1155/2014/61902 8

Kemenkes RI. (2014). Situasi dan Analisis Diabetes. Pusat Data Dan Informasi Kementerian Kesehatan RI. Diakses 8 Mei 2018 dari http://www.depkes.go.id/

Khoirunnisa, L (2016). Hubungan antara Kebiasaan Membaca Asmaul Husna Dengan Kecerdasan Emosional siswa kelas XI Madrasah Aliyah Nurul Ummah Yogyakarta. Jurnal Pendidikan Agama Islam, 14(1), 15-68. https://doi.org/10.14421/jpai.2017.1 41-04

Kementerian Agama Republik Indonesia. (2015). Al-qr'an dan Terjemahan. Edisi ke-5, Dharma Art, Jakarta.

Lindquist, R., Snyder, M., \& Tracy, M. F. (2014). Complementary \& Alternative Therapies in Nursing. $7^{\text {th }}$ Edition. Springer Publishing Company. USA

Petersmann, A., Nauck, M., Wieland, D, M., Kerner, W., Muller, U, A., Landgraf, R., Freckmann, G., Heinemann, L. (2018). Experimental and Clinical Endocrinology \& Diabetes. 126(07), 406-410. http://doi.org/10.1055/a0584-6223

Priya, G \& Klara, S. (2017) Mind Body Intraction and Mindfulness Meditation in Diabetes. Journal European Endocrniology. 14 (1); 35-41. http://doi.org/10.4103/22308210.192924.

Song, Y., Nam, S., Park, S.,Shin, I, S., \& Ku,B,J. (2017). The Impact of Social Support on Self-care of Patients With Diabetes: What Is the Effect of Diabetes Type? Systematic Review and Meta-analysis. The Diabetes Educator, 43(4), 396-412. https://doi.org/10.1177/0145721717 712457

Susanti, E. (2014). Pengaruh Latihan Pasrah Diri Terhadap Tingkat Stres dan Kadar Gula Darah pada Pasien Diabetes Melitus Tipe 2 di Rumah Sakit PKU Muhammadiyah Yogyakarta. Indonesian Journal Nursing Practice. Vol 1 (1). 78-91

Tao, X., Li, J., Zhu, X. et al. Association between socioeconomic status and metabolic control and diabetes complications: a cross-sectional nationwide study in Chinese adults with type 2 diabetes mellitus. Cardiovasc Diabetol. 15(61), 6-7. http://doi.org/10.1186/s12933-0160376-7

Walker, R.J., Gebregziabher, M., Harris, B.M., \& Egede, E. E. (2014). Independent effects of socioeconomic and psychological social determinants of health on self-care and outcomes in Type 2 diabetes. General Hospital Psychiatry. 36(6), 662-668. http://doi.org/10.1016/j.genhosppsy ch.2014.06.011

World Health Organization. (2016). Global Report on Diabetes. diakses 28 Agustus 2018 dari https://www.who.int/diabetes/global -report/en/ 